\title{
Adapting Soft Robotics Outreach to Teacher-Delivered Curriculum in the Virtual Classroom (Work in Progress)
}

\author{
Ms. Sapna Shah, Harvard University \\ Mr. Alex Beaudette, Harvard University \\ Mr. David R. Bergandine, University of Illinois Laboratory High School \\ Chemistry Teacher University Laboratory High School 1984 - 2021
}

\section{Savindi N. Devmal , University of Illinois Laboratory High School}

Savindi Devmal is a student at the University Laboratory High School in Urbana, IL. Savindi's interests include bioengineering and soft robotics, and she is the recipient of the Barbara Lazarus award to develop bioprinters for soft robotics applications. Savindi was also a participant in the Soft Robotics Toolkit pilot in October 2020.

\section{Prof. Conor Walsh P.E., Harvard University}

Conor is Assistant Professor of Mechanical and Biomedical Engineering at the Harvard School of Engineering and Applied Sciences and a Core Faculty Member at the Wyss Institute for Biologically Inspired Engineering at Harvard. He is the founder of the Harvard Biodesign Lab, which brings together researchers from the engineering, industrial design, medical and business communities to develop smart medical devices and translate them to industrial partners in collaboration with the Wyss Institute's Advanced Technology Team. Conor's research projects focus on wearable robotics to assist the disabled and able-bodied, as well as on tools for minimally invasive diagnosis and treatment of disease. His educational interest is in the area of medical device innovation where he mentors student design teams on projects with clinicians in Boston and in emerging regions such as India. Conor received his B.A.I and B.A. degrees in Mechanical and Manufacturing engineering from Trinity College in Dublin, Ireland, in 2003 and M.S. and Ph.D. degrees in Mechanical Engineering from the Massachusetts Institute of Technology in 2006 and 2010. Conor is Assistant Professor of Mechanical and Biomedical Engineering at the Harvard School of Engineering and Applied Sciences. He is also the founder of the Harvard Biodesign Lab, which brings together researchers from the engineering, industrial design, medical and business communities to develop smart medical devices and translate them to industrial partners in collaboration with the Wyss Institute's Advanced Technology Team. Conor received his B.A.I and B.A. degrees in Mechanical and Manufacturing engineering from Trinity College in Dublin, Ireland, in 2003 and M.S. and Ph.D. degrees in Mechanical Engineering from the Massachusetts Institute of Technology in 2006 and 2010. He has been the recipient of over a dozen invention, entrepreneurship, and student mentoring awards including the MIT $\$ 100 \mathrm{~K}$ business plan competition, Whitaker Health Sciences Fund Fellowship, and the MIT Graduate Student Mentor of the Year.

\section{Prof. Holly M. Golecki, University of Illinois at Urbana - Champaign}

Dr. Holly Golecki (she/her) is a Teaching Assistant Professor in Bioengineering at the University of Illinois Urbana-Champaign and an Associate in the John A Paulson School of Engineering and Applied Sciences at Harvard University. She holds an appointment at the Carle-Illinois College of Medicine in the Department of Biomedical and Translational Sciences. She is also a core faculty member at the Institute for Inclusion, Diversity, Equity, and Access in the College of Engineering. Holly studies biomaterials and soft robotics and their applications in the university classroom, in undergraduate research and in engaging K12 students in STEM. Holly received her BS in Materials Science and Engineering from Drexel University and her $\mathrm{PhD}$ in Engineering Sciences from Harvard University. 


\title{
Adapting Soft Robotics Outreach to a Teacher-delivered Curriculum in the Virtual Classroom (Work in Progress)
}

\begin{abstract}
Participation in educational robotics, tinkering, and making are common precursors to enrollment in engineering majors. By broadening the applications of robotics to human-centered designs, the field of soft robotics may be a platform to engage a diversity of students in K12 robotics and later, engineering majors. Until now, most K12 soft robotics activities were presented as practitioner-delivered outreach. This paper details development and pilot of a teacher facilitated Soft Robotics Toolkit program for K12 schools that includes a design thinking curriculum and a physical toolkit, specifically designed to complete in school or at home. For teachers to confidently deliver the emerging curriculum, we describe a teacher professional development to facilitate adoption of soft robotics topics into middle and high school classrooms. We provide reflections on the experience of the classroom teacher delivering the curriculum in the remote environment and results from a $9^{\text {th }}$ grade student in the course. This pilot will inform future work in assessing teacher confidence in teaching robotics and engineering design as well as the impacts of teacher-delivered soft robotics curricula on students.
\end{abstract}

\section{Introduction}

Participation in traditional educational robotics, tinkering, and making are common precursors to enrollment in engineering majors [1]. In recent years, the field of soft robotics has emerged as a method for robots to interface with humans or other delicate objects by replacing hard components with mechanically programmed polymers and flexible electronics [2]. By broadening the applications of robotics to human-centered design in healthcare [3] or marine exploration [4], soft robotics may be a platform to engage a greater diversity of students in K12 robotics and later, engineering majors. The accessibility of soft robot construction has led to the development of activities geared toward inspiring young students to experiment [5-8]. Until now, most K12 soft robotics activities were presented as practitioner-delivered outreach. While the connection between practitioners and students is invaluable, the reach of K12 soft robotics programs remains limited in this format.

This paper details the development and pilot of the Soft Robotics Toolkit curriculum that can be delivered remotely and a physical toolkit for teachers and students to build soft robots at school or at home. To increase accessibility and participation, we developed materials focused for both teachers and students. For teachers, we created a professional development workshop aimed at empowering teachers to bring soft robotics lessons into their classrooms. For students, we developed physical toolkits that enable students to learn soft robot fabrication, automation techniques and actuator design. In addition, a modular, design thinking curriculum for 6th through 9th grade students was developed to facilitate remote delivery of the course content. Here we detail the curriculum development and delivery process and reflections on the 
experience of the classroom teacher delivering the curriculum in the remote environment. By bringing robotics into children's homes we aim to break down many of the barriers to participation and meet the needs of remote learners.

\section{Goals and Objectives}

The goal of this project was to develop an online curriculum and physical toolkit to engage K12 teachers and students in soft robotics design projects. The Fall 2020 pilot consisted of two parts: a teacher workshop and a teacher facilitated lesson for students. Goals for each component of the pilot are outlined in Table 1.

Table 1. Goals for teacher and student soft robotics toolkit workshops.

\begin{tabular}{|c|c|}
\hline \multicolumn{2}{|r|}{ Professional development workshop for teachers } \\
\hline & $\begin{array}{l}\text { For teachers to: } \\
\text { - understand the benefits of exposing students to soft robotics. } \\
\text { - complete the physical builds included in the toolkit. } \\
\text { - become familiar with how to prepare for the program with students. } \\
\text { - feel inspired, motivated, and confident to bring soft robotics programs to their students. }\end{array}$ \\
\hline \multicolumn{2}{|r|}{ Teacher facilitated workshop for students } \\
\hline 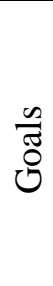 & $\begin{array}{l}\text { - Teacher successfully delivers the curriculum to their students. } \\
\text { - For students to learn about soft robots, human-centered design, and the engineering } \\
\text { design process. } \\
\text { - For students to successfully complete the toolkit building projects. } \\
\text { - For students to prototype a new design based on course lessons. }\end{array}$ \\
\hline
\end{tabular}

\section{Program description}

The COVID-19 pandemic has forced schools and robotics programs to transition to remote learning and making. This creates a challenge for facilitating hands-on projects and a significant disadvantage to students that benefit from tactile connection to classroom material. To address the timely needs of students and teachers during the pandemic, this curriculum consists of online resources and physical kits, delivered to students' homes, to facilitate remote instruction and at-home soft robot building.

\subsection{Curriculum Design}

The curriculum serves multiple purposes: to expose students to the field of soft robotics, engineering design, and technical aspects of robotic actuators and controls. To achieve this, thirteen lessons were developed for teachers to facilitate discussion, debate, and ideation around soft robots, their applications, and future uses. Lessons are divided into two phases: Phase I Starter Curriculum and Phase II Exploration Curriculum. Lessons are outlined in Table 2. 
Table 2. Soft Robotics Toolkit Lesson Outline

\begin{tabular}{|c|c|c|}
\hline No. & Lesson Title & Lesson Description \\
\hline \multicolumn{3}{|c|}{ Phase 1: Starter Kit } \\
\hline 1 & Introduction & $\begin{array}{l}\text { Introduces students to robots as devices that } \\
\text { - } \quad \text { sense-think and act on their own } \\
\text { - } \text { are made with rigid and soft materials } \\
\text { - how materials influence the performance of the robot }\end{array}$ \\
\hline 2 & Build a Soft Actuator & Students learn about silicone, mold making and casting and build soft actuators. \\
\hline 3 & $\begin{array}{l}\text { Bio-Inspiration: } \\
\text { Learning from Nature }\end{array}$ & $\begin{array}{l}\text { Students are introduced to the idea of bioinspiration or learning from nature. } \\
\text { They compare the manual gripper with the human hand to understand how we } \\
\text { can learn from nature as we design machines. }\end{array}$ \\
\hline 4 & $\begin{array}{l}\text { Building an } \\
\text { Autonomous gripper - } \\
\text { Part } 1\end{array}$ & $\begin{array}{l}\text { Build the electronics kit and learn how cables, motors and pulleys can be used to } \\
\text { move parts of a robot. }\end{array}$ \\
\hline 5 & $\begin{array}{l}\text { Building an } \\
\text { Autonomous gripper - } \\
\text { Part } 2\end{array}$ & $\begin{array}{l}\text { Build the programming kit and learn about sensing, control. Students are } \\
\text { introduced to Arduino programming. }\end{array}$ \\
\hline \multicolumn{3}{|c|}{ Phase 2: Exploration Kit } \\
\hline 6 & $\begin{array}{l}\text { Introducing the } \\
\text { Engineering Design } \\
\text { Process }\end{array}$ & $\begin{array}{l}\text { Students are introduced to the engineering design process, maker mindsets and } \\
\text { the soft robotic toolkit competition. }\end{array}$ \\
\hline 7 & $\begin{array}{l}\text { Understanding the } \\
\text { Problem }\end{array}$ & Students review the limits of their soft gripper and set a design challenge. \\
\hline 8 & Gathering Inspiration & $\begin{array}{l}\text { Students observe grippers in nature as well as some man-made soft grippers to } \\
\text { gather inspiration and understand how the structure of the actuator influences the } \\
\text { functional abilities of the gripper. }\end{array}$ \\
\hline 9 & Imagine & $\begin{array}{l}\text { Students begin by generating conceptual sketches of multiple ideas. Later, } \\
\text { students develop a detailed conceptual sketch of one idea they want to further } \\
\text { develop. }\end{array}$ \\
\hline 10 & Plan and Create & $\begin{array}{l}\text { Students convert their conceptual sketches into detailed drawings. They make } \\
\text { their designs tangible by building prototypes of their designs using simple } \\
\text { materials. }\end{array}$ \\
\hline 11 & Test and Improve & $\begin{array}{l}\text { Students test their new actuators. Based on feedback, students iterate on their } \\
\text { design. }\end{array}$ \\
\hline 12 & Final design & Students build 3D mold for the final design and cast silicone. \\
\hline 13 & Share & Students present their final projects and share their learnings/reflections. \\
\hline
\end{tabular}


In the Phase I starter kit, students were guided through the process of building silicone grippers, motorizing the gripper, and finally automating the gripping action with sensors. In addition, they learned about soft robotics, applications, and bioinspiration used by engineers. In the Phase II exploration kit, students were asked to find the limits of the device constructed in Phase I. A design thinking framework was used to guide students through redesign of a soft gripper to achieve a new and specific task, chosen by the students. Next, students looked to nature for inspiration to design grippers that could pick up new objects. Design Heuristics cards [9] were employed to facilitate design ideation. In lessons 9 through 11, students developed conceptual sketches, detailed drawings, and prototyped new gripper designs inspired by nature. Students were encouraged to iterate through multiple designs, as time and material allowed. Lastly, students presented their design to peers via video conferencing and to the research team in a "Design Journal".

\subsection{Toolkit}

The physical materials are divided into two kits. The first kit, we call the 'Introduction Kit', introduces students to the field of soft robotics while guiding them through a building process to construct a set of silicone grippers (Figure

1). The gripper build has three modes: manual actuation, motorized, and sensor actuated. Students work with pre-assembled and raw material components such as silicone, PCBs, motor, switches, various fasteners, and a mold for casting silicone. The second kit, we call the 'Exploration Kit', empowers students to materialize unique design ideas by working with raw materials and tools, commonly available in households or schools, such as paper,

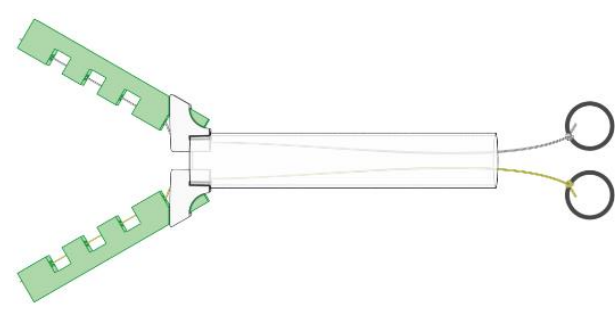

Figure 1. Schematic of silicone gripper configured for manual actuation. cardboard, string, silicone, playdoh, scissors, and a ruler. In this module, we encourage students to incorporate components from the Introduction kit into their final designs.

\subsection{Partner school}

University Laboratory High School on the campus of The University of Illinois UrbanaChampaign (UIUC) is a public high school in the state of Illinois. Both students and faculty have informal and formal connections with UIUC programs (academics, engagement, research, etc.). The students involved in this pilot program had some previous experience in outreach workshops. The instructor in this pilot program has had extensive experience as a participant, trainer, and developer of training workshops for science and engineering educators in K12.

\subsection{Teacher workshop}

A pilot teacher training workshop was facilitated via video conferencing. The teacher workshop was led by developers of the curriculum. The workshop lasted for 8 hours over 4 days with assignments between each session. Prior to the workshop, the toolkit and all prototyping 
materials were

mailed to the

teacher. Outside of

the workshop, Mr.

Bergandine spent

$\sim 10$ hours

preparing to

translate the

workshop to

students. He
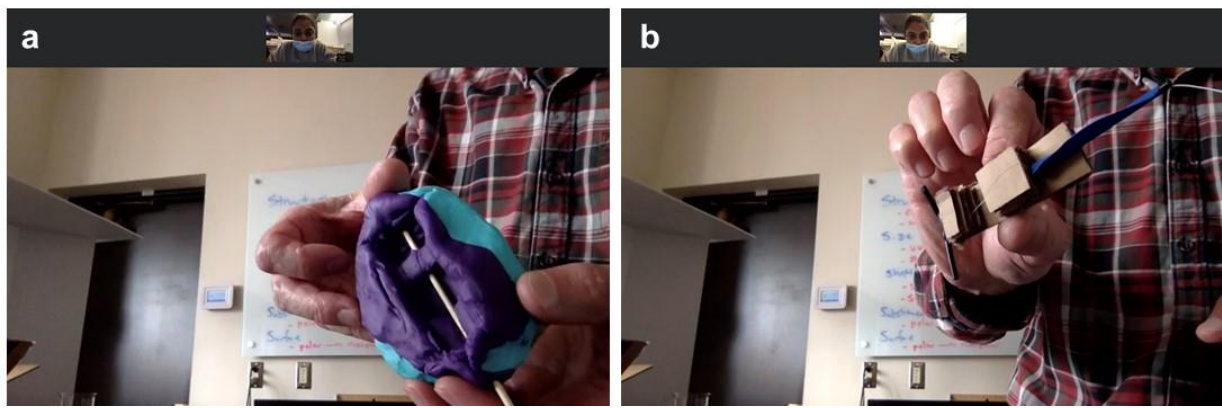

Figure 2. Teacher presenting (a) clay and (b) cardboard prototypes in the actuator design lesson of the teacher workshop.

reported that this would be a typical amount of time for him spent preparing new material for his classes. The teacher participant reviewed all lessons and completed the toolkit activities that included building a soft robotics gripper, automating the gripper, and redesigning the gripper for a specific task using the Exploration Kit (Figure 2).

\subsection{Student workshop}

Lessons were piloted over three weeks with 8th and 9th grade students and their teacher synchronously and asynchronously. Materials were mailed to the teacher and picked up by students. As the students would be working at home, all materials provided were skin-safe and easy to work with. Students began by building the manual gripper composed of silicone actuators. Figure 3 shows a manual gripper built by a student in the program (Lesson 2). After completing the autonomous gripper (Lessons 4, 5), students tested the limits of the gripper (Lesson 7). The following quotes and images are excerpts from one Design Journal completed in the pilot. The student noted in their Design Journal, "Because the gripper's actuators are long, it is hard to pick up very small objects. The relatively smooth surface of the actuators also make it hard to pick up smooth objects because the object just slips out of the gripper's grasp."
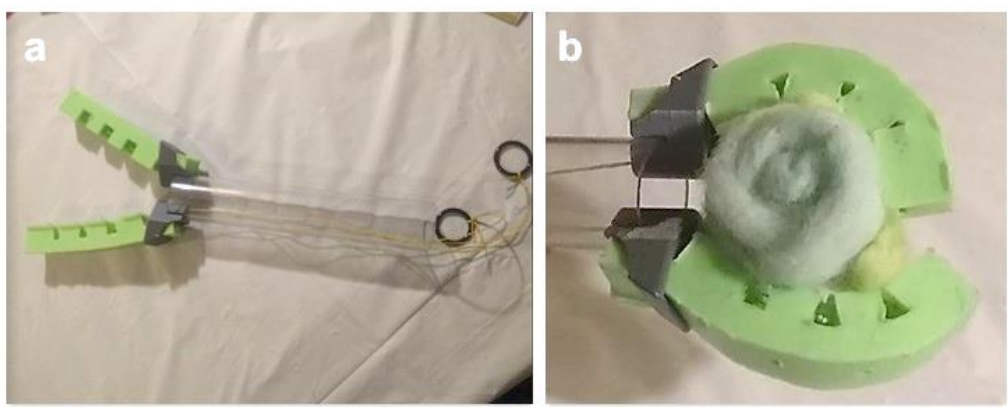

Figure 3. Starter Kit gripper built and assembled (a) and tested (b) by a student.

After completing Lesson 8 Gathering Inspiration and Lesson 9 Imagine, the student said, "My idea for a different gripper that can pick up smaller and smoother objects was inspired by two different things in nature and something humans have built before. The tentacle of an octopus inspired the bumpy surface of the actuators in my idea. This bumpy surface would help create the friction needed to pick up smooth objects. The human hand inspired the multiple actuators, and the placement of these actuators was inspired by claws in a claw machine." 
Figures 4 through 8 detail one student's design process to develop a gripper optimized to pick up a smooth, small pencil. Figure 4 shows the concept sketches by the student.
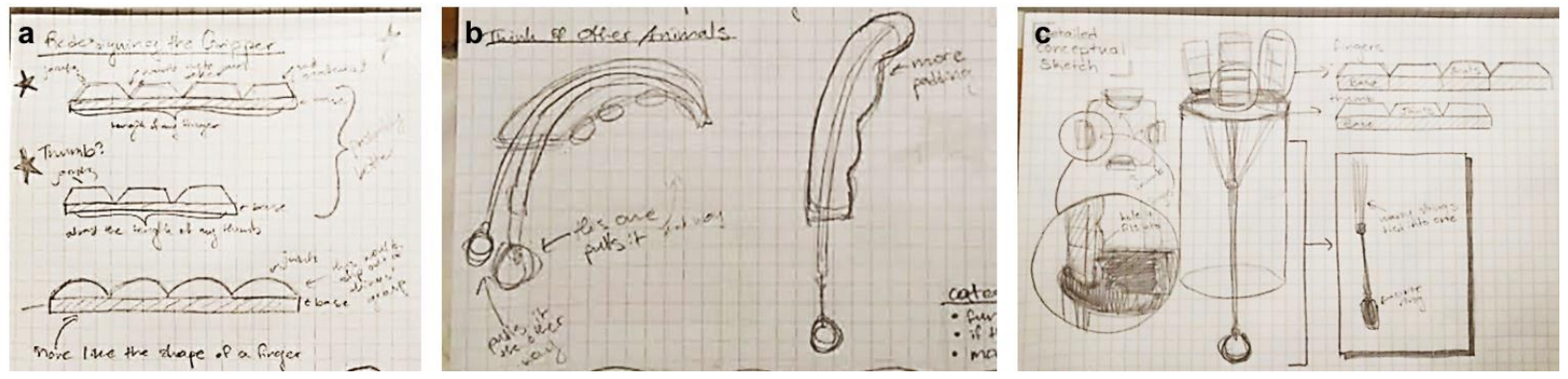

Figure 4. Student concept sketches for a soft robot gripper that can pick pencils.

About the design concept, the student said, "My new gripper will have four actuators placed in a formation that makes it similar to a claw in a claw machine. This formation along with all the strings connected to one ring will, in theory, help with control when picking up an object. Each actuator has bumps/texture that will help it pick up smooth objects, and the smaller scale should be able to help with picking up smaller objects." Next, the student converted concept sketches to detailed drawings and prototyped their actuator in cardboard.
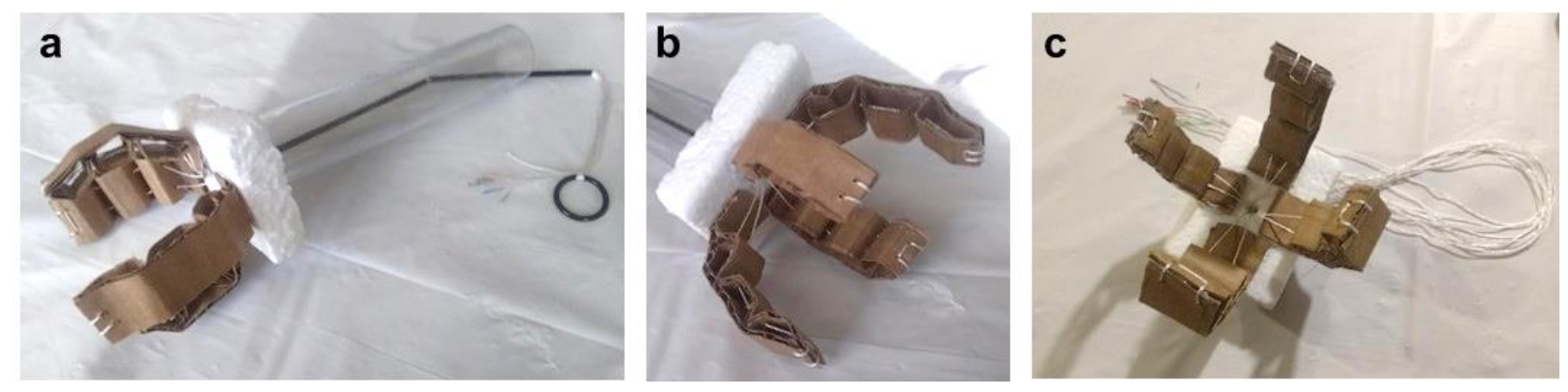

Figure 5. Three views of student's cardboard prototype.

After constructing the cardboard prototype (Figure 5), the student tested their design (Figure 6). They reported, "I tested my initial prototype by trying to pick up many different small things. I was able to pick up a few things like bottles and cotton ball-like objects. I was able to pick up tube-like things from the side, but it took a lot of effort to pick up pens and pencils. I think this difficulty will be solved once I make the actuators out of silicone, which would be much more flexible."

In Lesson 11 Test and Improve, the student reported design features they planned to change after prototype testing, "I also realized that having only one ring to control the gripper might be less versatile than it could be. I think if I use two rings to control
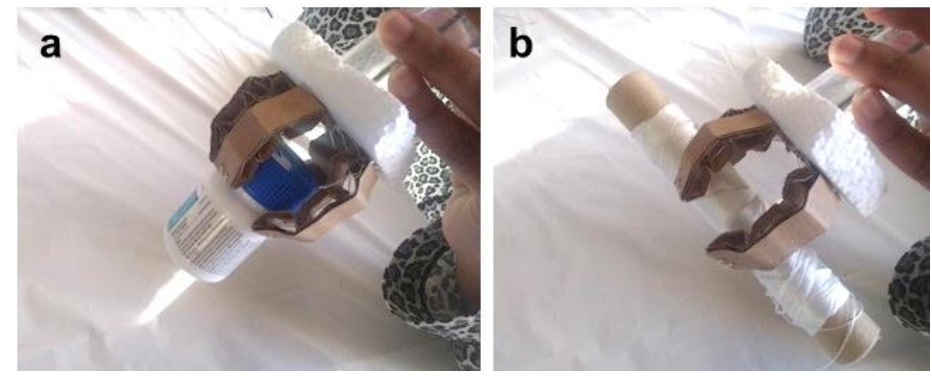

Figure 6. Student testing their cardboard prototype gripper. 
opposing actuators, it will make the gripper much more versatile and easier to control."

Lastly, students created clay impression molds and cast silicone to build silicone grippers. Figure 7 shows the student's final design (Figure 7a) and demonstrates it can pick a pencil (Figure 7b) and marker (Figure 7c).
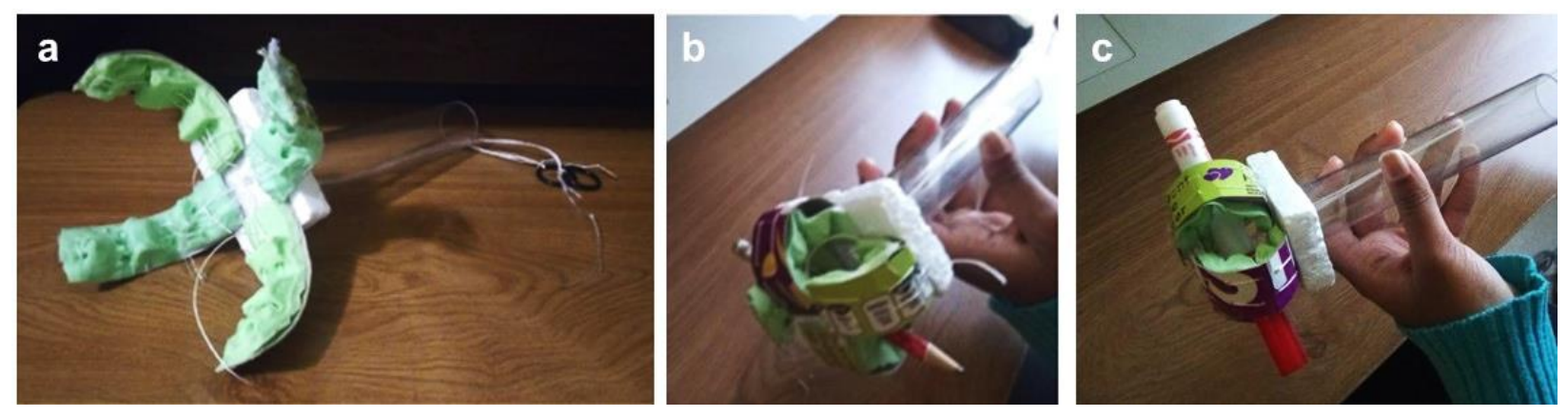

Figure 7. (a) Soft robotic gripper designed and built by a student in the pilot program. (b) Student demonstrating the gripper picking a pencil.

\section{Findings}

After the pilot, we asked the teacher to reflect on his experience learning and delivering the curriculum. His feedback on the Teacher workshop and Student workshop are detailed below in Table 3.

Table 3. Teacher feedback on workshops in the Soft Robotics Toolkit pilot.

\begin{tabular}{|c|c|}
\hline \multicolumn{2}{|r|}{ Facilitation } \\
\hline 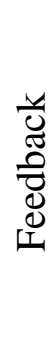 & $\begin{array}{l}\text { - Many of the activities involved in the teacher and student training were made } \\
\text { easier by having access to laptops and the internet, so being fully remote did not } \\
\text { require tools or access that would not have been used otherwise. } \\
\text { - When making the different grippers, an instructor around in person would be able } \\
\text { to help a lot more easily compared to remote. However, being at home and being } \\
\text { forced to figure out most things on our own was beneficial for students. }\end{array}$ \\
\hline \multicolumn{2}{|r|}{ Student Experience } \\
\hline 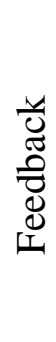 & $\begin{array}{l}\text { - Students are intrinsically motivated to design and build robots, and the notion of } \\
\text { soft components in robotics is novel for most students. } \\
\text { - There was very little soft material to work with, because of this, accuracy was } \\
\text { important. You have to be extremely careful and put a lot of thought into what you } \\
\text { are doing. Planning is very important as well. All of this planning and making sure } \\
\text { not to make huge mistakes can be challenging for students new to soft robotics. }\end{array}$ \\
\hline
\end{tabular}




\section{Conclusions and Future Work}

We conclude with developer reflections recommendations for future virtual, hands-on workshops for K12 students in Table 4. This pilot will inform larger-scale offerings both in person and in the virtual environment.

Table 4. Curriculum designer reflections from pilot offering

\begin{tabular}{|l|l|}
\hline \multicolumn{1}{|c|}{ Topic } & \multicolumn{1}{c|}{ Reflection } \\
\hline $\begin{array}{l}\text { Capturing } \\
\text { student work }\end{array}$ & $\begin{array}{l}\text { As part of our exploratory module we wanted students to learn documenting their } \\
\text { design process using a design journal. To make this process easier we created a design } \\
\text { journal template for students, we prompted students to take pictures of their work and } \\
\text { complete the relevant aspects of their journal. }\end{array}$ \\
\hline Teacher & $\begin{array}{l}\text { We used our limited teacher workshop time to familiarize the teacher with the build } \\
\text { process and asked the teacher to review the other aspects of the lessons } \\
\text { independently. Consequently, during the classroom sessions we observed that the } \\
\text { teacher focused much more on the build process and relatively less on the lessons. On } \\
\text { reflection, I wonder if our unilateral focus on the build process translated into the } \\
\text { teacher's time spent on build vs lesson? }\end{array}$ \\
\hline $\begin{array}{l}\text { Idea } \\
\text { Generation }\end{array}$ & $\begin{array}{l}\text { As part of the exploratory module we challenged the students to re-design the gripper } \\
\text { they had made in the introductory module such that it is more effective and useful. } \\
\text { The students were quick to identify challenges with the current gripper design. } \\
\text { However, they struggled with idea generation. Looking back I think we did not } \\
\text { anticipate students would struggle with idea generation and our curriculum did not } \\
\text { provide enough support for students to brainstorm multiple, varied ideas. }\end{array}$ \\
\hline
\end{tabular}

This pilot will additionally inform future work in assessing teacher confidence in teaching soft robotics and engineering design as well as the impacts of teacher-delivered soft robotics curricula on students. Future measures may include teacher self-efficacy, student tinkering self-efficacy, and STEM identity as methods to probe the impact of the curriculum on teachers, students, and classrooms either in person or virtually.

\section{Acknowledgements}

This work was supported by the Office of Naval Research (award \# N000141912386), National Science Foundation (award \#1830896) and the Tata Trusts through The Lakshmi Mittal and Family South Asia Institute.

\section{References}

1. G. Potvin et al., "Gendered interests in electrical, computer, and biomedical engineering: intersections with career outcome expectations," IEEE Trans. Educ., vol. 61, no. 4, pp. 298-304, Nov. 2018, doi: 10.1109/TE.2018.2859825.

2. C. Laschi, B. Mazzolai, and M. Cianchetti, "Soft robotics: Technologies and systems pushing the boundaries of robot abilities," Sci. Robot., vol. 1, no. 1, p. eaah3690, Dec. 2016, doi: 10.1126/scirobotics.aah3690. 
3. P. Polygerinos, N. Correll, S.A. Morin, B. Mosadegh, C.D. Onal, K. Petersen, M. Cianchetti, M.T. Tolley, R.F. Shepherd, "Soft Robotics: Review of Fluid-Driven Intrinsically Soft Devices; Manufacturing, Sensing, Control, and Applications in HumanRobot Interaction: Review of Fluid-Driven Intrinsically Soft Robots," Adv. Eng. Mater., vol. 19, no. 12, p. 1700016, Dec. 2017, doi: 10.1002/adem.201700016.

4. B.T. Phillips, K.P. Becker, S. Kurumaya, K.C. Galloway, G. Whittredge, D.M. Vogt, C.B. Teeple, M.H. Rosen, V.A. Pieribone, D.F. Gruber and R.J. Wood, "A Dexterous, Glove-Based Teleoperable Low-Power Soft Robotic Arm for Delicate Deep-Sea Biological Exploration," Sci Rep, vol. 8, no. 1, p. 14779, Dec. 2018, doi: 10.1038/s41598-018-33138-y.

5. D. P. Holland, E. J. Park, P. Polygerinos, G. J. Bennett, and C. J. Walsh, "The Soft Robotics Toolkit: Shared Resources for Research and Design," Soft Robotics, vol. 1, no. 3, pp. 224-230, Sep. 2014, doi: 10.1089/soro.2014.0010.

6. D. P. Holland, C. Abah, M. Velasco-Enriquez, M. Herman, G.J. Bennett, E.A. Vela, and C.J. Walsh, "The Soft Robotics Toolkit: Strategies for Overcoming Obstacles to the Wide Dissemination of Soft-Robotic Hardware," IEEE Robot. Automat. Mag., vol. 24, no. 1, pp. 57-64, Mar. 2017, doi: 10.1109/MRA.2016.2639067.

7. D. P. Holland, G. J. Bennett, G. M. Whitesides, R. J. Wood, and C. J. Walsh, "The 2015 Soft Robotics Competition [Competitions]," IEEE Robot. Automat. Mag., vol. 23, no. 3, pp. 25-27, Sep. 2016, doi: 10.1109/MRA.2016.2587959.

8. J. Zhang, A. Jackson, N. Mentzer, and R. Kramer, "A Modular, Reconfigurable Mold for a Soft Robotic Gripper Design Activity," Front. Robot. AI, vol. 4, p. 46, Sep. 2017, doi: 10.3389/frobt.2017.00046.

9. A. Ostrowski, J. Lee, S. Daly, A. Huang-Saad, and C. Seifert, "Design in biomedical engineering: student applications of design heuristics as a tool for idea generation," American Society for Engineering Education. Columbus, Ohio, 2017. 